\title{
Development of a restriction length polymorphism combined with direct PCR technique to differentiate goose and Muscovy duck parvoviruses
}

\author{
Chun-He WAN ${ }^{1,2)}$, Hong-Mei CHEN ${ }^{1)}$, Qiu-Ling FU'1), Shao-Hua SHI ${ }^{1)}$, Guang-Hua FU' ${ }^{1)}$, Long-Fei $\mathrm{CHENG}^{1)}$, \\ Cui-Teng $\mathrm{CHEN}^{1)}$, Yu HUANG ${ }^{1) *}$ and Kai-Hui $\mathrm{HU}^{2) *}$ \\ ${ }^{1)}$ Institute of Animal Husbandry and Veterinary Medicine, Fujian Academy of Agricultural Science/Fujian Animal Disease Control \\ Technology Development Center, Fuzhou 350013, China \\ ${ }^{2)}$ College of Life Sciences, Fujian Agriculture and Forestry University, Fuzhou 350002, China
}

(Received 3 June 2015/Accepted 5 January 2016/Published online in J-STAGE 5 February 2016)

ABSTRACT. A restriction fragment length polymorphism combined with direct PCR technique to differentiate goose and Muscovy duck parvoviruses (GPV and MDPV) was developed based on comparison of the NS gene of GPV and MDPV. Both GPV and MDPV genomic DNA can be amplified with 641 bp using the specific PCR primers. The PCR fragments can be cut into 463 bp and 178 bp only in the case of MDPV-derived PCR products, whereas the GPV-derived PCR products cannot. The method established in this study can be used to differentiate GPV and MDPV with high specificity and precision, by using a direct PCR kit and QuickCut enzyme, as quickly as conventional PCR.

KEY WORDS: direct PCR, goose parvovirus, muscovy duck parvovirus, restriction fragment length polymorphism

doi: 10.1292/jvms.15-0326; J. Vet. Med. Sci. 78(5): 855-858, 2016

Waterfowl parvovirus can cause disease with high mortality and morbidity in goslings and Muscovy ducklings. Genomic analysis and an antibody neutralization test revealed that the waterfowl parvovirus can be divided into two groups: the goose parvovirus (GPV) group and Muscovy duck parvovirus (MDPV) group. GPV can cause highly contagious and fatal disease in goslings, Muscovy ducklings, swans and Anser cygnoides [2, 3, 5, 8, 9], whereas MDPV only causes disease in Muscovy ducklings [2, 3, 8, 10].

GPV and MDPV have single-stranded DNA genomes of about $5.1 \mathrm{~kb}$ in length and contain two major open reading frames (ORFs) [3, 5, 6, 8, 9, 12]. The left ORF encodes nonstructural (NS) proteins NS1 and NS2, derived from the same gene, which is involved in viral replication and regulatory functions. The right ORF encodes three capsid proteins: VP1, VP2 and VP3. VP1, VP2 and VP3 are derived from the same gene via differential splicing. Futhermore, VP2 and VP3 are contained within the carboxyl terminal portion of VP1.

The NS genes of GPV and MDPV share more than $80.0 \%$ nucleotide identity, and GPV and MDPV shared related antigenic features as evaluated by cross-neutralization $[3,14]$. Traditional diagnostic methods have been employed for detection GPV and MDPV, such as the agar gel precipita-

\footnotetext{
*Correspondence to: Huang, Y., Institute of Animal Husbandry and VeterinaryMedicine,FujianAcademyofAgriculturalScience,Pudang Jin'an, Fuzhou, 350013, China. e-mail: huangyu_815@163.com, $\mathrm{Hu}, \mathrm{K}$., College of Life Sciences, Fujian Agriculture and Forestry University, Jinshan, Fuzhou, 350002, China.

e-mail: huhk2015@126.com

(C)2016 The Japanese Society of Veterinary Science

This is an open-access article distributed under the terms of the Creative Commons Attribution Non-Commercial No Derivatives (by-nc-nd) License $<$ http://creativecommons.org/licenses/by-nc-nd/4.0/>.
}

tion, the virus neutralization test, the virus antigen-based enzyme-linked immunosorbent assay (ELISA), the indirect fluorescent antibody test, polymerase chain reaction, realtime PCR and the loop-mediated isothermal amplification method (LAMP) $[1,4,11,14]$. These reported methods have been associated with various problems, including poor sensitivity and specificity for differentiation GPV and MDPV, especially when GPV and MDPV co-infection occurred in the same Muscovy duck flocks.

Here, we reported a restriction fragment length polymorphism combined with direct PCR technique to differentiate GPV and MDPV based on the conserved molecular characteristic regions after comparison with the NS gene sequences from GPV and MDPV references strains downloaded from GenBank. The method established in this study can be used to differentiate GPV and MDPV as quickly as the conventional PCR by using direct PCR and QuickCut enzyme digestion, with greater specificity and precision.

The NS gene sequences from GPV and MDPV strains were downloaded from GenBank and compared with each other by using DNASTAR Lasergene (v7.1) (DNAStar Inc., Madison, WI, U.S.A.). At the position 973 in their NS genes, MDPV has GAATTC, which can be recognized by the EcoR I restriction enzyme. However, GPV has GAGTTC, which cannot be recognized by the EcoR I restriction enzyme (see Fig. 1). The differences between GPV and MDPV can be recognized as conserved molecular characteristic regions. A specific pair of primers (NSF1, 5'- CAATGGGCTTTTACCAATATGC-3' and NSR1, 5'- ATTTTTCCCTCCTCCCACCA-3') was designed to cover this specific region for their NS gene which generates an expected PCR product of 641 bp. Using the target-specfic primers NSF1 and NSR1, all GPV isolates were confirmed to have no EcoR I restriction enzyme sites, whereas all MDPV isolates were confirmed to have only one EcoR I restriction enzyme site. 


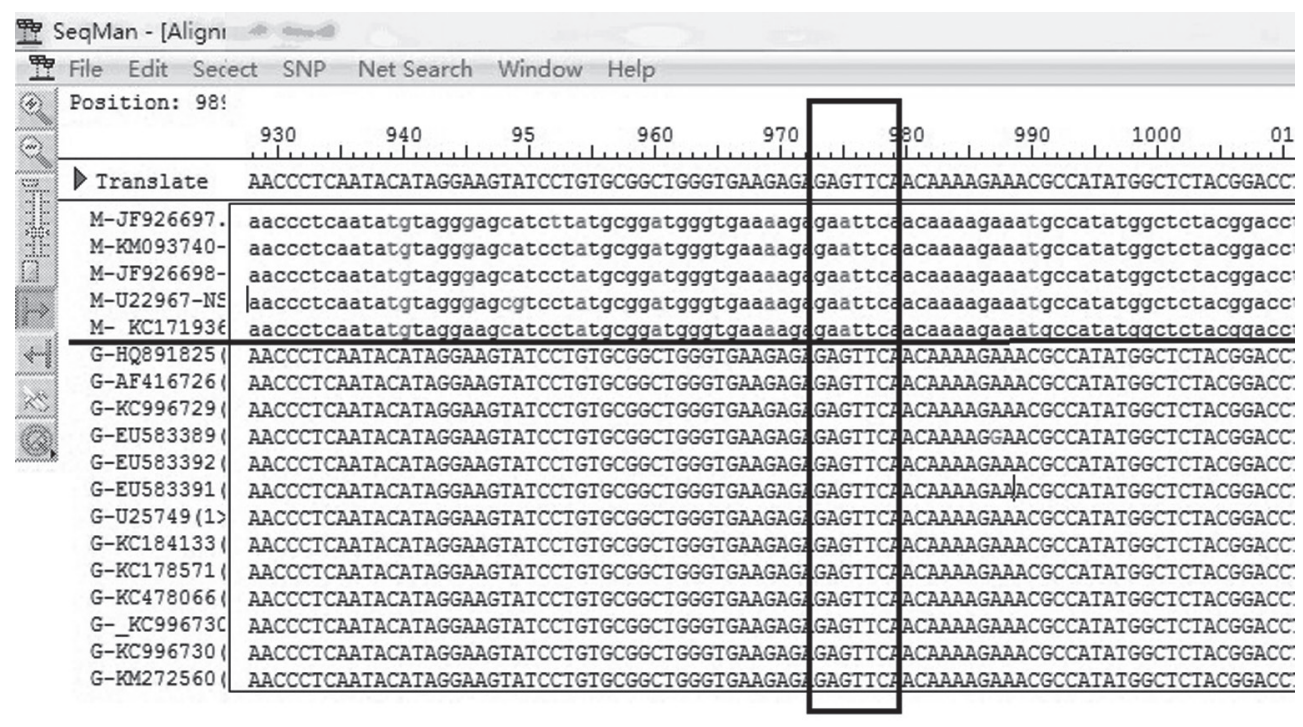

Fig. 1. Comparison of the NS gene of the GPV and MDPV reference strains. All the MDPV reference strains contained the EcoR I enzyme site GAATTC at position 973, with M in front of the GenBank accession number. All the GPV reference strains contained GAGTTC, with G in front of the GenBank accession number.

The MDPV-derived PCR products can be digested by EcoR I enzyme into two fragments of $463 \mathrm{bp}$ and $178 \mathrm{bp}$ in length, respectively. However, the GPV-derived PCR products cannot be digested by EcoRI enzyme and should potentially remain $641 \mathrm{bp}$ in length.

Eleven samples (liver and spleen samples) collected from Muscovy duck between 3 and 25 days with typical waterfowl parvoviruses infection clinical signs included watery diarrhea, sneezing and locomotory dysfuctions, on commercial Muscovy duck farms in Fujian, Southeast China, from January to April 2013 and analyzed by using the established polymerase chain reaction-restriction enzyme fragment length polymorphism (PCR-RFLP). Viruses were isolated from all eleven samples by using 10-day Muscovy duck embryos collected from the Muscovy farm, which had no previous history with MDPV or GPV infections and did not use an attenuated vaccine against MDPV or GPV.

A Tissue Direct PCR Kit (Omega Bio-Tek, Norcross, GA, U.S.A.) was used to prepare the template DNA from tissues for PCR without DNA isolation, according to the manufacturer's instructions. The optimal PCR conditions for detection of GPV and MDPV were determined to be $95^{\circ} \mathrm{C}$ for $4 \mathrm{~min}$; 40 cycles of $94^{\circ} \mathrm{C}$ for $30 \mathrm{sec}, 54^{\circ} \mathrm{C}$ for $30 \mathrm{sec}$ and $72^{\circ} \mathrm{C}$ for $35 \mathrm{sec}$ and a final extension step at $72^{\circ} \mathrm{C}$ for $7 \mathrm{~min}$. The optimized reaction was carried out in a $25 \mu \mathrm{l}$ final reaction volume containing $12.5 \mu l$ of kit-supplied $2 \times$ Taq Master Mix, $1 \mu l$ concentration of each forward and reverse primer (each $20 \mu \mathrm{M}$ ), $4 \mu l$ DNA templates and $6.5 \mu l$ distilled water to adjust the final volume to $25 \mu \mathrm{l}$.

The QuickCut ${ }^{\mathrm{TM}}$ EcoR I (Takara, Dalian, China) digestion reactions were prepared according to the manufacturers's instructions. 10× QuickCut Buffer $2 \mu l, 1 \mu l$ QuickCut EcoR I enzyme, $10 \mu l$ PCR products and $5 \mu l$ distilled water to adjust the final volume to $20.0 \mu l$ and then incubate at $37^{\circ} \mathrm{C}$ for $5 \mathrm{~min}$. Prior to incubation, the PCR tubes were centrifuged at $4,000 \mathrm{rpm}$ for $10 \mathrm{sec}$. At the end of the reaction, $10 \mu \mathrm{l}$ of samples were loaded onto a $1.5 \%(\mathrm{~W} / \mathrm{V})$ agarose gel for electrophoresis.

Common waterfowl infectious diseases (DNA viruses and bacterial pathogens) were used to analyze the specificity of the established method, such as duck circovirus (DuCV), goose circovirus (GoCV), duck plague virus (DPV), egg drop syndrome virus (EDSV), Escherichia coli (E. coli), Salmonella, Riemerella anatipestifer (R.A.) and also Pasteurella Multocida (P.M.). The E. coli (CVCC3732), Salmonella (CVCC3758), R.A. (CVCC3773), Pasteurella Multocida (CVCC458), DPV (CEC 19950150) and EDSV (CVCC AV183) reference strains were collected from the China Veterinary Culture Collection Center (CVCC). The DuCV (GenBank ID GQ423747) and GoCV (GenBank ID GU320569) reference strains were identified by us at the Institute of Animal Husbandry and Veterinary Medicine, Fujian Academy of Agricultural Science, Fuzhou, China.

Only GPV and MDPV virus were tested positive with 641 bp fragments under the optimized PCR conditions. No crossamplification occurred with the reference strains templates, including DuCV, GoCV, DPV, EDSV, E. coli, Salmonella, R.A. and P.M. (see Fig. 2).

After the QuickCut EcoR I digestion reactions, the MDPV-derived PCR products could be cut $463 \mathrm{bp}$ and $178 \mathrm{bp}$ fragments, whereas the GPV-derived PCR products could not be cut remained $641 \mathrm{bp}$. The PCR products derived from GPV and MDPV co-infection samples yielded three fragments, 641 bp, 463 bp and 178 bp (see Fig. 3).

Agarose gel electrophoresis showed that six of the eleven samples yielded $641 \mathrm{bp}$ fragments after PCR amplification. After EcoR I digestion, four of the six samples could be digested, and they generated two fragments, one with $463 \mathrm{bp}$ 


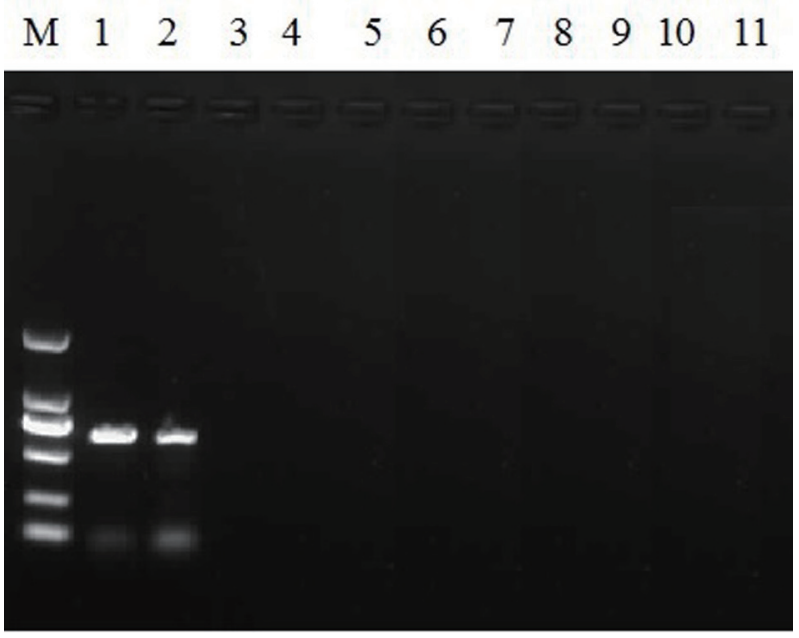

Fig. 2. PCR amplification for common infectious diseases. M, DL 2000 DNA Marker; 1, GPV; 2, MDPV; 3, DuCV; 4, GoCV; 5, DPV; 6, EDSV; 7, E. coli; 8, Salmonella; 9, R.A.; 10, P.M.; 11, negative control.

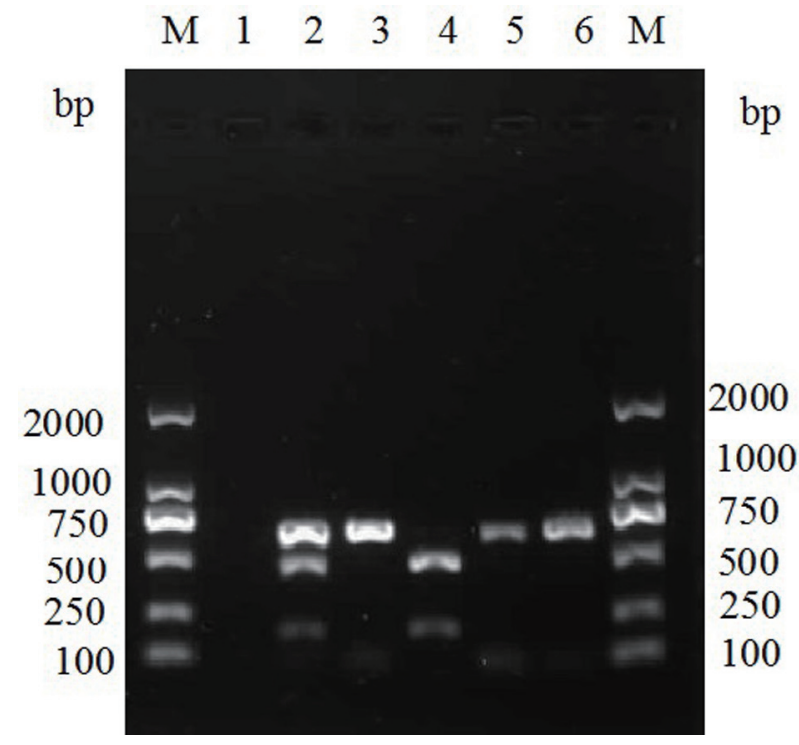

Fig. 3. Detection and differentiation of GPV, MDPV and GPVMDPV co-infection by using EcoR I digestion analysis. M, DL 2000 DNA Marker; 1, negative control; 2, GPV and MDPV PCR products digested by EcoR I; 3, GPV PCR products digested by EcoR I; 4, MDPV PCR products digested by EcoR I; 5, GPV PCR products; 6, MDPV PCR products.

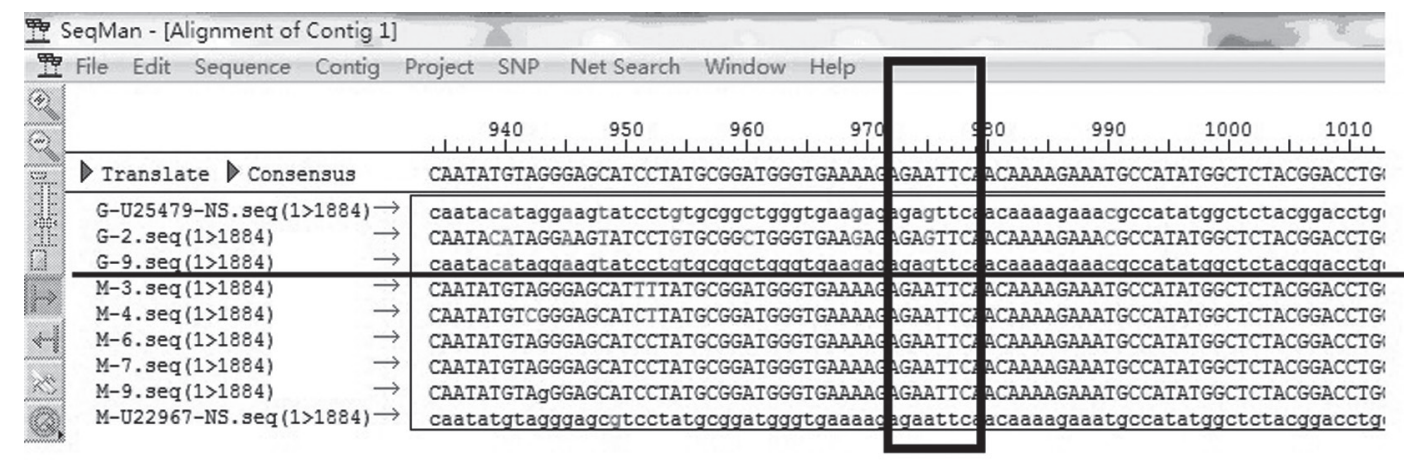

Fig. 4. Analysis of cloned sequences from the clinical samples. The reference strains (were G-U25479 for GPV; M-U22967 for MDPV). Four MDPV-positive samples contained the GAATTC EcoR I restriction site as expected (samples 3, 4, 6 and 7), while the GPV-positive sample contained the GAGTTC (sample 2), and the co-infection samples contained both GAATTC and GAGTTC (sample 9).

and one with $178 \mathrm{bp}$ fragments, one of the six samples yielded only $641 \mathrm{bp}$ fragments, and only one of the six samples had $641 \mathrm{bp}, 463 \mathrm{bp}$ and $178 \mathrm{bp}$ fragments, which means that this sample was co-infected with GPV and MDPV (see Fig. 3).

The positive samples PCR amplicons were cloned and sequenced, and the sequenced data and GPV and MDPV reference strains were analyzed with the DNASTAR Lasergene (v7.1) software. Four MDPV-positive samples contained only the GAATTC EcoR I restriction site as expected (samples 3, 4, 6 and 7), while the GPV-positive sample contained GAGTTC (sample 2), and the co-infection samples contained both GAATTC and GAGTTC (sample 9) (see
Fig. 4). We concluded that the difference between MDPV with GAATTC and GPV with GAGTTC at position 973 can be recognized as a genetic marker in waterfowl parvoviruses. We isolated MDPV from four clinical samples (samples 3, 4, 6 and 7), GPV from one clinical sample (sample 2) and GPV and MDPV (co-infection) from one clinical sample (sample 9), and they shared $100 \%$ with the PCR-RFLP results described in this study.

Restriction enzyme analysis of the viral genome has been widely applied to the differential diagnosis of different parvovirus species belonging to the genus Parvovirus within the Parvoviridae family, such as canine parvovirus and 
mink enteritis virus [13]. PCR-RFLP analysis was reported firstly used to distinguish GPV and MDPV in Thailand by using HincII, BglII and EcoR1 restriction enzymes [7]. In this study, we established a new PCR-RFLP method with the EcoR I restriction enzyme digested directly to differentiate GPV and MDPV infection status, saving time, money and labor, by comparison with the GPV and MDPV reference strains with greater precision.

In conclusion, a PCR-RFLP method to differentiate GPV and MDPV by using a tissue directs PCR kit and QuickCut enzyme (only needs 5 min more for digestion without any PCR products clean up). The method described in this study was shown to be specific, sensitive and repeatable and to be simple and low cost compared with the normal procedure; it also does not require purification of the PCR products, which is especially suitable for determination of the GPV and MDPV co-infection status. Furthermore, the established method can provide a rapid qualitative and reliable diagnosis for GPV and MDPV as quickly as conventional PCR methods with greater precision.

ACKNOWLEDGMENTS. This work was supported by the China Agriculture Research System (CARS-43), Special Fund for Agro-scientific Research in the Public Interest (201003012), Fujian Natural Sciences Foundation (2015J01114), and the Hundred Talents Program (Fujian Academy of Agriculture Sciences) (YC2015-12). The founders had no role in study design, data collection and analysis, decision to publish, or preparation of the manuscript.

\section{REFERENCES}

1. Alexandrov, M., Alexandrova, R., Alexandrov, I., Zacharieva, S., Lasarova, S., Doumanova, L., Peshev, R. and Donev, T. 1999. Fluorescent and electron-microscopy immunoassays employing polyclonal and monoclonal antibodies for detection of goose parvovirus infection. J. Virol. Methods 79: 21-32. [Medline] [CrossRef]

2. Chang, P. C., Shien, J. H., Wang, M. S. and Shieh, H. K. 2000. Phylogenetic analysis of parvoviruses isolated in Taiwan from ducks and geese. Avian Pathol. 29: 45-49. [Medline] [CrossRef]

3. He, Y., Shaozhou, W., Bai, X. and Zhang, Y. 2014. Complete genomic sequences analysis of five waterfowl parvoviruses. Acta Vet. Zoo. Sin. 45: 1837-1843 (in Chinese).

4. Ji, J., Xie, Q. M., Chen, C. Y., Bai, S. W., Zou, L. S., Zuo, K. J.,
Cao, Y. C., Xue, C. Y., Ma, J. Y. and Bi, Y. Z. 2010. Molecular detection of Muscovy duck parvovirus by loop-mediated isothermal amplification assay. Poult. Sci. 89: 477-483. [Medline] [CrossRef]

5. Shao, H., Lv, Y., Ye, J., Qian, K., Jin, W. and Qin, A. 2014. Isolation of a goose parvovirus from swan and its molecular characteristics. Acta Virol. 58: 194-198. [Medline] [CrossRef]

6. Shien, J. H., Wang, Y. S., Chen, C. H., Shieh, H. K., Hu, C. C. and Chang, P. C. 2008. Identification of sequence changes in live attenuated goose parvovirus vaccine strains developed in Asia and Europe. Avian Pathol. 37: 499-505. [Medline] [CrossRef]

7. Sirivan, P., Obayashi, M., Nakamura, M., Tantaswasdi, U. and Takehara, K. 1998. Detection of goose and Muscovy duck parvoviruses using polymerase chain reaction-restriction enzyme fragment length polymorphism analysis. Avian Dis. 42: 133-139. [Medline] [CrossRef]

8. Wan, C., Chen, H., Fu, Q., Fu, G., Cheng, L., Shi, S., Huang, Y. and $\mathrm{Hu}, \mathrm{K} .2015$. Genomic characterization of goose parvovirus and Muscovy duck parvovirus co-infection in Fujian, China. Kafkas Univ. Vet. Fak. Derg. 21: 923-928.

9. Wan, C., Huang, Y., Shi, S., Fu, G., Cheng, L., Chen, H., Fu, Q., Chen, C. and Hu, K. 2016. Complete Genome Sequence of Goose Parvovirus Isolated from Anser cygnoides in China. Kafkas Univ. Vet. Fak. Derg. 22: 155-158.

10. Wang, S., Cheng, X. X., Chen, S. Y., Zhu, X. L., Chen, S. L., Lin, F. Q. and Li, Z. L. 2013. Genetic characterization of a potentially novel goose parvovirus circulating in Muscovy duck flocks in Fujian Province, China. J. Vet. Med. Sci. 75: 1127-1130. [Medline] [CrossRef]

11. Woźniakowski, G., Samorek-Salamonowicz, E. and Kozdruń, W. 2012. Quantitative analysis of waterfowl parvoviruses in geese and Muscovy ducks by real-time polymerase chain reaction: correlation between age, clinical symptoms and DNA copy number of waterfowl parvoviruses. BMC Vet. Res. 8: 29. [Medline] [CrossRef]

12. Zádori, Z., Stefancsik, R., Rauch, T. and Kisary, J. 1995. Analysis of the complete nucleotide sequences of goose and muscovy duck parvoviruses indicates common ancestral origin with adeno-associated virus 2. Virology 212: 562-573. [Medline] [CrossRef]

13. Zhang, C., Yu, Y., Yang, H., Li, G., Yu, Z., Zhang, H. and Shan, H. 2014. Development of a PCR-RFLP assay for the detection and differentiation of canine parvovirus and mink enteritis virus. J. Virol. Methods 210C: 1-6. [Medline]

14. Zhang, Y., Li, Y., Liu, M., Zhang, D., Guo, D., Liu, C., Zhi, H., Wang, X., Li, G., Li, N., Liu, S., Xiang, W. and Tong, G. 2010. Development and evaluation of a VP3-ELISA for the detection of goose and Muscovy duck parvovirus antibodies. J. Virol. Methods 163: 405-409. [Medline] [CrossRef] 